\title{
A Parallel Approach to Mobile Affixation in Huave
}

\author{
Sam Zukoff \\ Leipzig University
}

\section{Introduction}

This paper examines the system of "mobile affixation" in Huave (isolate, Mexico), specifically the San Francisco del Mar variety described and analyzed by Kim $(2008,2010,2015 \mathrm{a}, \mathrm{b})$. The central properties of Huave's mobile affixation system can be exemplified by the behavior of the Completive / $t$ / (CP) when it attaches to simple bases, as shown in (1). When CP / $t /$ is affixed to a $\mathbf{C}(\ldots) \mathbf{V}$ base (1a), it appears after the base (i.e., as a "suffix"). On the other hand, when it is affixed to a $\mathbf{V}(. ..) \mathbf{C}$ base (1b), it instead surfaces before the base (as a "prefix"). This mobility is, at least in part, conditioned by phonological factors: namely, the affix lands wherever it can avoid a cluster, or the automatic epenthesis that would repair it (Kim, 2008, 2010). ${ }^{1}$

\section{Completive / $\mathbf{t}$ / mobile affixation}

a. $\quad \mathbf{C}(\ldots) \mathbf{V}$ bases: $m o^{h} k o-t$ 's/he lay face down' $\quad\left[* t(a)-m o^{h} k o\right]$

b. $\mathbf{V}_{(. . .)} \mathbf{C}$ bases: $\boldsymbol{t}$-uc 's/he ate' $\quad\left[{ }^{*} u c-(i) t\right]$

[(Kim, 2010:140)]

This phonological characterization is consistent with the behavior of the two other possible base types, $\mathbf{V}_{(\ldots)} \mathbf{V}$ and $\mathbf{C}(\ldots) \mathbf{C}^{2}{ }^{2}$ In both of these cases, the structures resulting from prefixation and suffixation would be equivalent with respect to cluster phonotactics: when both edges are vowels (2a), no cluster would arise either way; when both edges are consonants (2b), a cluster, which must be resolved via epenthesis, would arise either way. Since the relevant phonological factors do not come into play in these types, they reveal that suffixation is the "default" behavior for these affixes.

\section{Right-orientation of mobile affixes}

a. $\quad \mathbf{V}(. .$.$) V bases: u j u-\boldsymbol{m} \quad$ (no gloss) $\quad\left[{ }^{*} \boldsymbol{m}\right.$ - $\left.u j u\right] \quad(/ \mathrm{m} / \Leftrightarrow$ subordinate)

b. $\quad \mathbf{C}(\ldots)$ C bases: $n-u k^{w} a l-\underline{a} s$ 'I am pregnant' $\quad\left[{ }^{*} s \underline{a}-n-u k^{w} a l\right] \quad(/ \mathrm{s} / \Leftrightarrow 1 \mathrm{st}$ PERSON, $/ \mathrm{n} /([n]) \Leftrightarrow \operatorname{staTIVE})$

This distribution can be derived in the phonology if the ranking fragment $\left\{{ }^{*} \mathrm{CC} \gg \mathrm{DEP}\right\}$ (defined in (3)) dominates right-oriented alignment constraints (McCarthy \& Prince, 1993) referencing individual affixes. $\left\{{ }^{*} \mathrm{CC} \gg\right.$ DEP $\}$ is independently motivated by the language's ban on consonant clusters (Kim, 2008:21).

a. $\quad$ *CC: Assign one violation * for each sequence of two adjacent consonants.

b. DEP: Assign one violation * for each inserted segment.

Kim $(2008,2010)$ shows that this can be implemented in a cyclic cophonology approach. This approach specifies a sequence of attachment for all morphemes, which are divided up into "Layers", as schematized in (4). (Some layers require further internal structure.) The Layers marked with dotted lines contain mobile affixes. In this approach, mobile affixes are morphemes whose exponent is a single consonant, and whose cophonology is the one in (5a), where the anti-cluster constraints outrank the relevant alignment constraint. Non-mobile affixes are either those with the cophonology in (5b), where alignment outranks the anti-cluster constraints, or those which consist of just a vowel, and hence do not conflict with anti-cluster constraints.

\footnotetext{
* Thank you to Yuni Kim, Jochen Trommer, Jelena Grofulovic, the audience at AMP 2020, and audiences at Leipzig and Berkeley. All mistakes and bad ideas are of my own doing.

1 Kim (2015a,b) proposes an alternative analysis based on avoidance of initial (non-root) vowels. It is not clear if this could be made consistent with the approach developed here. This must be deferred to future work.

2 Because of the way theme vowels work in the language (see footnote 3), no simple base ever has the shape $\mathbf{C}(. ..) \mathbf{C}$.

(C) 2021 Sam Zukoff

Proceedings of AMP 2020
} 
Huave's "layered" morphology (Kim, 2015a:114)

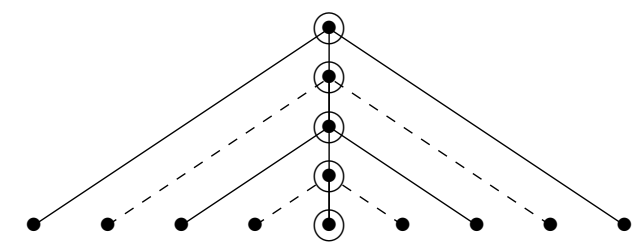

L4 L3 L2 L1 $\quad$ STEM L1 L2 L3 $\quad$ L4
(5)

Types of cophonologies

a. Mobile cophonologies:

$\{* \mathrm{CC} \gg$ DEP $\} \gg$ ALIGN-R

b. Non-mobile cophonologies: ALIGN-L/R $\gg\left\{{ }^{*} \mathrm{CC} \gg D E P\right\}$

Recently, Zukoff (to appear) has argued for a fully parallel approach to morpheme ordering based around the "Mirror Alignment Principle" (see $\$ 3.2$ below). In this framework, there is no cyclic concatenation in the morphology (or the phonology, for that matter): all morphemes in a word are present simultaneously in an unordered phonological input, and surface order is determined by constraint interaction (mostly but not exclusively by alignment constraints) in a parallel phonological computation. This is obviously not compatible with Kim's implementation. The primary goal of this paper, therefore, is to demonstrate that an equivalent analysis can be implemented in parallel, in a manner consistent with Zukoff's approach.

The parallel analysis introduced here is based on "articulated alignment", whereby every morpheme is indexed to its own (crucially gradient) alignment constraint (e.g. ALIGN-CP-R, Align-Fut-L). Following Zukoff, morphemes are unordered in the phonological input, and surface order is computed entirely in parallel. In this analysis, mobile affixes are morphemes with a single-consonant exponent and a right-oriented alignment constraint that ranks below $\left\{{ }^{*} \mathrm{CC} \gg \mathrm{DEP}\right\}$. These are the same defining properties as in Kim's analysis, except that there must be a single place in the language-wide ranking for $\left\{{ }^{*} \mathrm{CC} \gg \mathrm{DEP}\right\}$.

Throughout the paper, I will focus on demonstrating that a single, consistent constraint ranking, comprised of just alignment constraints and the fragment $\left\{{ }^{*} \mathrm{CC} \gg \mathrm{DEP}\right\}$, can derive the full range of mobility patterns. It is not the goal of this paper to argue against Kim's analysis. Nevertheless, I will point out one place in particular where the analyses differ, namely, the treatment of the Completive, Stative, and Subordinate morphemes (§2.4). In Kim’s analysis, these three morphemes act as a single unified class (though perhaps only epiphenomenally). On the other hand, the parallel analysis identifies an ordering difference that shows that the Subordinate patterns differently from the other two in terms of alignment. This is a desirable result, as Completive and Stative seem to pattern together against Subordinate in both meaning and function.

The parallel alignment analysis is laid out in detail in §2. It starts with forms that have a single mobile affix ( $\S 2.1-2.2)$, and builds up to more complex forms with multiple mobile affixes ( $\S 2.3-2.5)$. In $\S 3$, I'll also show that the parallel analysis may provide a principled distinction between mobile and immobile affixes, which is not inherent to the cyclic analysis, related to morphosyntactic structure via Zukoff's Mirror Alignment Principle and considerations of Base-Derivative faithfulness (Benua, 1997). The paper ends with a brief conclusion in $\S 4$, which suggests that the parallel analysis more directly captures a previously unnoticed generalization about the stability of left/right order between affixes in the language. ${ }^{3}$

\section{Parallel analysis of mobile affixation}

2.1 Basic mobility: Base + Aspect The mobile affixes which Kim ascribes to "Layer 1" are listed in (6). The morphemes Completive, Stative, and Subordinate cannot co-occur, and have largely equivalent ordering properties. For the time being, I will refer to these collectively as the "Aspect" [AsP] morphemes.

\footnotetext{
3 Before proceeding, two preliminary notes are in order. First, all forms are given in IPA notation, as in Kim (2015a,b). See $\operatorname{Kim}(2010: 134$, fn. 2) for the translation between her earlier conventions and IPA. Candidate outputs are shown without the results of allophonic processes (palatalization, diphthongization; see Kim 2008). Surface forms are accompanied by a phonetic transcription reflecting these processes. Epenthetic vowels are italicized and/or underlined.

The second point regards "theme vowels" (see Kim, 2008: esp. Ch. 6). In Huave, specific verb forms take either a prefixal theme vowel [a] or [u], or a suffixal theme vowel whose quality is determined by vowel harmony. The choice of theme vowel is to some extent related to (in)transitivity (ibid.) or event structure (Yuni Kim, p.c.). For simplicity, I treat theme vowels as if they form an unbreakable, unanalyzed constituent with the root, which, following a suggestion by Yuni Kim, I refer to as the "base" (with the internal boundary marked with "+"). But this is an area that requires substantial further attention. For example, Kim $(2015 \mathrm{a}, \mathrm{b})$ treats the "suffixal theme vowels" as epenthetic vowels. This is attractive, but incompatible with my analysis, which would then wrongly predict, e.g., ${ }^{k} r$-e-mo ${ }^{h} k$ instead of $i-m o^{h} k+o-r(14)$.
} 
(6) Layer 1 mobile affixes (Kim, 2010:139)
a. $/ \mathrm{t} / \quad[\mathrm{CP}]$ Completive
b. $/ \mathrm{n} / \quad[\mathrm{sT}]$ Stative
c. $/ \mathrm{m} / \quad[\mathrm{sB}] \quad$ Subordinate $(/ \mathrm{n} /$ in 1 st person [ $[\mathrm{SB} 1])$
d. $/ \mathrm{r} / \quad[2 \mathrm{I}] \quad$ 2nd Person Intransitive (occurs only in conjunction with 2 nd Person /e/)

Default right-alignment of mobile affixes can be seen from $\mathbf{V}_{(. . .)} \mathbf{V}$ bases (8). None of the phonotactic issues that drive mobility are applicable, so the decision is made by the relevant alignment constraint. Since these morphemes end up on the right, they must have right-oriented alignment constraints (7). $\mathbf{C}_{(\ldots)} \mathbf{V}$ bases (9) likewise show perfect right-alignment of the Aspect morphemes. Since prefixation (9b) violates both ALIGNAsp-R and ${ }^{*} \mathrm{CC}$ (see (3a) above), both alignment and phonotactics advocate suffixation in this case.

(7) Align(Aspect, R; Wd, R) [Align-Asp-R]: Assign one violation mark * for each segment which intervenes between the right edge of the Aspect morpheme and the right edge of the word.

Mobile affixes to $V_{(\ldots)} V$ bases

i. uj+u-m (ujum)

circle-SB

(no gloss)

[(Kim, 2010:149, ex. 28)]

ii.

\begin{tabular}{|ll||lr|}
\hline \multicolumn{2}{|c||}{$/ \mathrm{uj}+\mathrm{u}, \mathrm{m}_{\mathrm{SB}} /$} & \multicolumn{2}{l|}{ ALIGN-AsP-R } \\
\hline \hline a. & uju-m & & \\
\hline b. & m-uju & $* ! * *$ & $(\mathrm{u}, \mathrm{j}, \mathrm{u})$ \\
\hline
\end{tabular}

(9)

\section{Mobile affixes to $\mathbf{C}(\ldots) \mathrm{V}$ bases}

i. $\quad \mathrm{mo}^{\mathrm{h}} \mathrm{k}+\mathrm{o}-\mathrm{t} \quad\left(m o^{h} k o t\right)$

face.down-CP

's/he lay face down'

[(Kim, 2010:140, ex. 12h)]

ii.

\begin{tabular}{|c|c|}
\hline$/ \mathrm{mo}^{\mathrm{h}} \mathrm{k}+\mathrm{o}, \mathrm{t}_{\mathrm{CP}} /$ & ALIGN-ASP-R \\
\hline a. $\quad \mathrm{mo}^{\mathrm{h}}$ ko-t & 1 \\
\hline t-moh ko & $! * ! * * *$ \\
\hline
\end{tabular}

In $\mathbf{V}_{(. .)} \mathbf{C}$ bases (10), ALIGN-Asp-R and ${ }^{*} \mathrm{CC}$ are at odds, since right-aligning the Aspect morpheme creates a cluster (10a). This conflict could be resolved either by deploying the optimal suffixal alignment and epenthesizing to resolve the cluster (10b) or by flopping the affix to the opposite side where it can attach without phonotactic complications (10c). Huave chooses the latter. This behavior is affix mobility. Since mobility is preferred to epenthesis, DeP also outranks ALIGN-AsP-R.

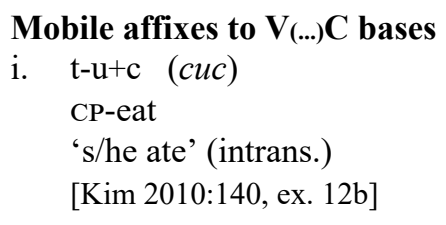

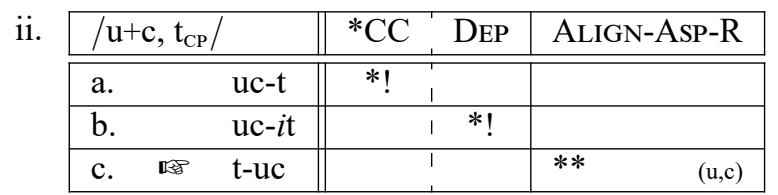

While no base (root + theme vowel) both begins and ends in a consonant $\left(\mathbf{C}_{(. . .)} \mathbf{C}\right)$, this configuration does occur when multiple affixes are present (see §2.4). In these cases, schematized in (11), the ${ }^{*} \mathrm{CC}$ problem arises regardless of attachment site. The alignment analysis (whether cyclic or parallel) rightly predicts that the affix will surface to the right in these cases. Prefix (11c/d) and suffix candidates (11a/b) respectively tie on either *CC or DEP, and the tie is broken by lower-ranked ALIGN-AsP-R in favor of the suffix (11b). From these examples, we see that epenthesis is preferred to creating a cluster: ${ }^{*} \mathrm{CC} \gg \operatorname{DEP}(12)$.

(11)

Hypothetical mobile affixation to $\mathrm{C}_{(. . .)} \mathrm{C}$ base

\begin{tabular}{|ll||l|l|lr|}
\hline \multicolumn{2}{|l||}{$/ \mathrm{CVC}, \mathrm{t}_{\mathrm{CP}} /$} & ${ }^{*} \mathrm{CC}$ & DEP & \multicolumn{2}{|c|}{ ALIGN-ASP-R } \\
\hline \hline a. & CVC-t & $* !$ & & & \\
\hline b. & CVC- $i \mathrm{t}$ & & $*$ & & \\
\hline c. & $\mathrm{t}-\mathrm{CVC}$ & $* !$ & & $* * *$ & $(\mathrm{CvC})$ \\
\hline d. & $\mathrm{ti}-\mathrm{CVC}$ & & $*$ & $* ! * * *$ & $(i, \mathrm{cvc})$ \\
\hline
\end{tabular}

\author{
Ranking: \\ $* \mathrm{CC} \gg$ DeP $\gg$ Align-Asp-R
}


2.2 Mobility of the 2nd Person Intransitive 2nd person intransitive forms, illustrated in (13), are marked by two Layer 1 morphemes: a fusional 2nd person intransitive marker / $/$ ( abbrev. " $2 \mathrm{r}$ "), and a general 2nd person agreement marker /e/ (abbrev. " 2 "). ${ }^{4} 2$ /e/ always surfaces to the left of the base, but the position of 2I / r / varies by base shape: with $\mathbf{C}(\ldots) \mathbf{V}$ bases (13a), 2I /r/ surfaces at the right edge; but with $\mathbf{V}($...) $\mathbf{C}$ bases (13b), $2 \mathrm{I} / \mathrm{r} /$ surfaces between $2 / \mathrm{e} /$ and the base. That is to say, 2 /e/ doesn't show mobility (always a prefix),${ }^{5}$ but $2 \mathrm{I} / \mathrm{r} /$ does. This is exactly what we expect if mobility is driven by phonotactic pressure to avoid clusters: a consonantal affix moves, because it would create a cluster in its otherwise preferred position; but a vocalic affix always stays in its preferred location, because it will never create a cluster.

Mobility of the 2nd person intransitive in the atemporal paradigm

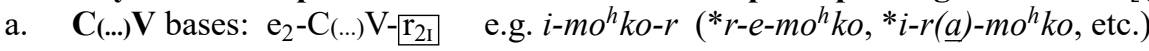

b. $\quad \mathbf{V}(. ..) \mathrm{C}$ bases: $\mathrm{e}_{2}-\mathrm{r}_{2 \mathrm{I}}-\mathrm{V}(\ldots) \mathrm{C} \quad$ e.g. $i-r-u c \quad\left({ }^{*} i-u c-(i) r,{ }^{*} u c-i-r\right.$, etc. $)$

This behavior can be modeled using multiple alignment constraints, in conjunction with *CC and DEP. 2 /e/ is unwaveringly prefixal, so it must have a left-alignment constraint: ALIGN-2-L. While alternatives exist at the moment, 2I / r/ does have a right-alignment constraint: ALIGN-2I-R. These two constraints, regardless of ranking, derive the $\mathbf{C}(\ldots) \mathbf{V}$ case (14). Candidate (14c) $e$-moh ${ }^{h} k o-r$ perfectly left-aligns $2 / \mathrm{e} /$ and perfectly right-aligns $2 \mathrm{r} / \mathrm{r} /$. Because the base ends in a vowel, right-alignment of $2 \mathrm{r} / \mathrm{r} /$ does not raise any phonotactic problems. All other candidates fare worse on alignment, and many have phonotactic problems too.

\section{2nd person intransitives to $\mathbf{C}_{(. . .)} \mathrm{V}$ bases}

i. $\quad$ e-mo ${ }^{\mathrm{h}} \mathrm{k}+\mathrm{o}-\mathrm{r} \quad\left(\right.$ imo $^{h}$ kor $)$

2-face.down-2I

'you (sg.) lie face down'

[(Kim, 2010:140, ex. 12j)]

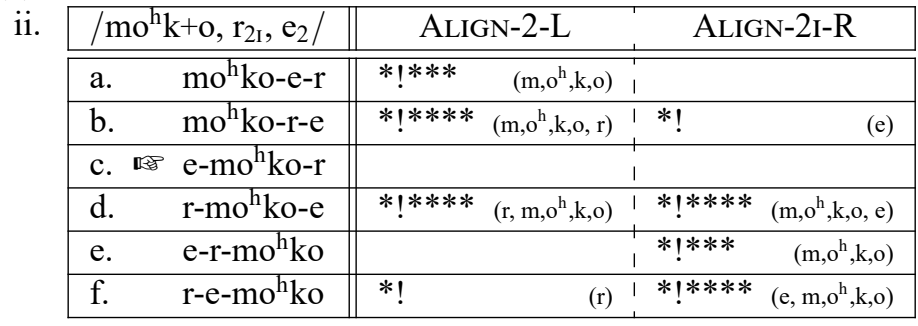

With $\mathbf{V}_{(\ldots)} \mathbf{C}$ bases, the desired right-alignment of 2r $/ \mathrm{r} /(17 \mathrm{c})$ would create a consonant cluster. Since other orderings can avoid creating a cluster, this candidate order is discarded. There are two main options for reordering: (i) move 2r $/ \mathrm{r} /$ leftward or (ii) move 2 /e/ rightward. Displacement of 2r $/ \mathrm{r} /$ is preferred: among the phonotactically sound candidates, (17e) [e-r-u-c] is preferred to (17a) [uc-e-r]. This secures the ranking in (15). Since mobility is phonotactically driven here, as evidenced by the preference for (17e) [e-r-u-c] over (17c) [e-uc- $(i) \mathrm{r}],\left\{{ }^{*} \mathrm{CC} \gg \mathrm{DEP}\right\}$ must also dominate ALIGN-2I-R (16).

Ranking: Align-2-L $\gg$ Align-2I-R

Ranking: *CC $\gg$ DEP $\gg$ ALIGN-2I-R

\section{2nd person intransitives to $\mathrm{V}_{(. . .)} \mathrm{C}$ bases}

i. e-r-u+c (iruc) ii.

2-2I-eat

'you (sg.) eat' (intrans.)

[(Kim, 2010:140, ex. 12d)]

\begin{tabular}{|c|c|c|c|c|c|}
\hline$/ \mathrm{u}+\mathrm{c}, \mathrm{r}_{2 \mathrm{I}}, \mathrm{e}_{2} /$ & \multirow[t]{2}{*}{${ }^{*} \mathrm{CC} / \mathrm{DEP}$} & \multicolumn{2}{|c|}{ ALIGN-2-L } & \multicolumn{2}{|c|}{ ALIGN-2I-R } \\
\hline uc-e-r & & $* ! *$ & $(\mathrm{u}, \mathrm{c})$ & & \\
\hline uc- $(i) \mathrm{r}-\mathrm{e}$ & $* !$ & l $*$ !**(*) & $(\mathrm{u}, \mathrm{c},(i), \mathrm{r})$ & $*$ & (e) \\
\hline e-uc- $(i) \mathrm{r}$ & $* !$ & i & & & \\
\hline d. $\quad$ r-uc-e & & 1*!** & $(\mathrm{r}, \mathrm{u}, \mathrm{c})$ & $* * *$ & $(\mathrm{u}, \mathrm{c}, \mathrm{e})$ \\
\hline e. ${ }^{\prime}$ e-r-uc & & 1 & & & $(\mathrm{u}, \mathrm{c})$ \\
\hline f. r-e-uc & & I*! & $(\mathrm{r})$ & $* * *$ & $(e, u, c)$ \\
\hline
\end{tabular}

\footnotetext{
4 The 2 morpheme has two surface variants: [i], which appears (roughly) in word-initial position; and [e], which appears elsewhere. Kim (2008:250) identifies its underlying representation as /i/, with the [e] allomorph surfacing only "in the presence of the completive and subordinate affixes". However, if its UR is instead /e/, we can derive the [i] variant with something like a morpheme-specific context-sensitive phonological raising process $\left(/ \mathrm{e}_{2} / \rightarrow[\mathrm{i}] / \#_{-}\right)$.

5 Kim (2008:346-350,2010:155-157) mentions limited variability in the position of the 2 morpheme in conjunction with the Subordinate. This appears to be based on morphological reanalysis, not affix mobility proper.
} 
2.3 Multiple mobility with $2 I / r /$ and Asp Now consider what happens when two mobile affixes cooccur. 2nd person intransitives can be marked for aspect, as in the completive form t-e-moh ${ }^{h} \mathrm{ko-r}(18)$.

$$
\begin{aligned}
& \text { 2nd person intransitive completives to } \mathbf{C}_{(\text {(...) }} \mathbf{V} \text { bases } \\
& \mathrm{t} \text {-e-mo }{ }^{\mathrm{h}} \mathrm{k}+\mathrm{o}-\mathrm{r} \quad\left(\text { cemo }^{h} k o r\right) \text { 'you (sg.) lay face down' } \\
& \text { CP-2-face.down-2I [(Kim, 2010:140, ex. 12k)] }
\end{aligned}
$$

As already established, both Aspect and 2r / r/ have right-alignment constraints. Likewise, both are single consonants, and respond to the same phonotactic conditions. Since only one morpheme can attain wordfinal position (assuming no coalescence), their relative left/right order tells us the ranking of their alignment constraints. In optimal candidate (20c) $t-e-m o^{h} k o-r, 2 \mathrm{I} / \mathrm{r} /$ (successfully) surfaces in word-final position, whereas CP / $t /$ is displaced all the way to word-initial position. This requires the ranking in (19).

Ranking: ALIGN-2I-R $\gg$ ALIGN-AsP-R

\begin{tabular}{|c|c|c|c|c|}
\hline$/ \mathrm{mo}^{\mathrm{h}} \mathrm{k}+\mathrm{o}, \mathrm{r}_{2 \mathrm{I}}, \mathrm{e}_{2}, \mathrm{t}_{\mathrm{CP}} /$ & *CC DEP & ALIGN-2-L & ALIGN-2I-R & ALIGN-AsP-R \\
\hline mo ${ }^{h}$ ko-t-e-r & I & $* * ! * * *\left(\mathrm{~m}, \mathrm{o}^{\mathrm{h}}, \mathrm{k}, \mathrm{o}, \mathrm{t}\right)$ & & $(\mathrm{e}, \mathrm{r})$ \\
\hline b. $\quad \mathrm{mo}^{\mathrm{h}}$ ko-r-e-t & 1 & $* * ! * * *\left(\mathrm{~m}, \mathrm{o}^{\mathrm{h}}, \mathrm{k}, \mathrm{o}, \mathrm{r}\right)$ & $(e, t)$ & \\
\hline c. $\mathrm{t}-\mathrm{e}-\mathrm{mo}^{\mathrm{h}} \mathrm{ko}-\mathrm{r}$ & 1 & (t) & & $* * * * * *\left(\mathrm{e}, \mathrm{m}, \mathrm{o}^{\mathrm{h}}, \mathrm{k}, \mathrm{o}, \mathrm{r}\right)$ \\
\hline r-e-mo ${ }^{h}$ ko-t & 1 & (r) & $* ! * * * * *\left(\mathrm{e}, \mathrm{m}, \mathrm{o}^{\mathrm{h}}, \mathrm{k}, \mathrm{o}, \mathrm{t}\right)$ & \\
\hline e-moh ${ }^{\mathrm{h} o-t-o r}$ & $* !$ & & & $(o, \mathrm{r})$ \\
\hline e-mo ${ }^{h}$ ko-t-r & $* !$ & & & (r) \\
\hline
\end{tabular}

Tableau for 2nd person intransitive completives to $\mathbf{C}_{(. . .)} \mathbf{V}$ bases

In most languages, the result of this competition would be a form like ${ }^{*} e-m o^{h} k o-t(o) r(20 \mathrm{e} / \mathrm{f})$, where both affixes end up as suffixes, in the order determined by the alignment ranking. This would violate either DEP (20e) or * $\mathrm{CC}(20 \mathrm{f})$, but ordering considerations would prevail. What's different in Huave is the tolerance of mobility in the service of phonological problems. Because the morphology happens to furnish an additional vowel (the 2 morpheme /e/), the cluster problems faced by $(20 \mathrm{e}, \mathrm{f})$ can be avoided by "movement" of one of the affixes: either $\mathrm{CP} / \mathrm{t} /$ could move left, before 2 /e/ (20c); or 2 /e/ could move right, between the mobile affixes (20a). If ALIGN-2-L $\gg$ ALIGN-Asp-R (which follows from transitivity; cf. (15) and (19)), leftward displacement of $\mathrm{CP} / \mathrm{t} /$ (20c) will be preferred. Note, nonetheless, that ALIGN-2-L satisfaction is not perfect. The $2 / \mathrm{e} /$ morpheme is still displaced from the left edge by $\mathrm{cP} / \mathrm{t} /$, just minimally so. This violation is driven by the higher ranking of $\left\{{ }^{*} \mathrm{CC} \gg \mathrm{DEP}\right\}$. The resulting order is determined by optimizing alignment over whatever candidates remain. This leaves us with the ranking in (21).

2nd person intransitive completives of $\mathbf{V}_{(\ldots)} \mathbf{C}$ bases, e.g. $t-e-r-u c$ (22), follow from the same ranking. Here, the two available vowels are both on the left side of the base, and therefore the two consonantal affixes surface on that side. Nevertheless, the relative linear order of the two consonantal affixes is maintained: $2 \mathrm{I} / \mathrm{r} /$ is further right than CP / $t$ /, because ALIGN-2I-R dominates ALIGN-AsP-R.

Ranking: ${ }^{*} \mathrm{CC} \gg \mathrm{DEP} \gg$ ALIGn-2-L $\gg$ ALIGN-2I-R $\gg$ ALIGN-AsP-R

2nd person intransitive completives to $\mathrm{V}_{(\text {....) }} \mathrm{C}$ bases

i. t-e-r-u+c (ceruc) 'you (sg.) ate' (intrans.) CP-2-2I-eat [(Kim, 2010:140, ex. 12e $)]$

ii.

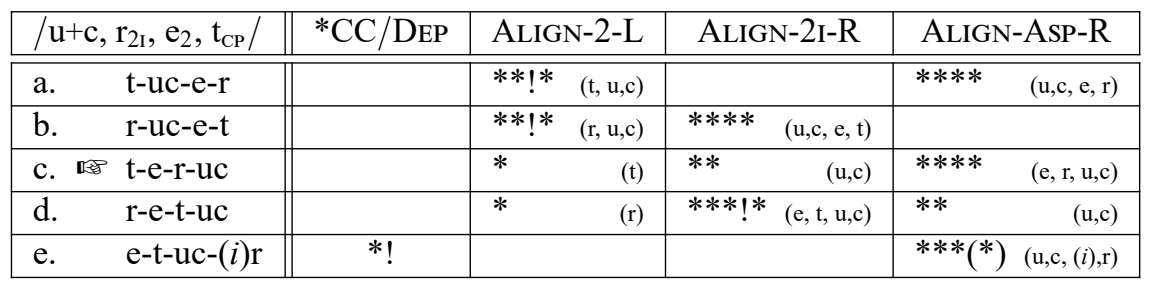


2.4 Mobile 1st person /s/ and its interaction with "Aspect" The last mobile affix is the 1st person agreement morpheme /s/ (abbrev. "1"). Kim assigns it to Layer 3, because it tends to occur "outside" of the Layer 1 and Layer 2 affixes. (In fact, it is the only Layer 3 affix.) The Layer 2 affix relevant here is the prefixal Future marker /i/. Huave's morphology prevents precise minimal pairs, but the mobility of $1 / \mathrm{s} / \mathrm{can}$ be seen in the contrast between the prefixal realizations in $\mathbf{V}_{(\text {...) }} \mathbf{C}$ bases (23) and suffixal realizations in $\mathbf{C}(\ldots.) \mathbf{V}$ stems [root (+ theme vowel) + intransitive suffix /u/] (24). (Examples from Kim 2008:249, 252.)

$$
\begin{aligned}
& \text { Prefixal /s/ to } \mathbf{V}_{(\ldots)} \mathbf{C} \text { bases } \\
& \text { a. } \quad \mathbf{S}-\mathrm{a}+{ }^{\mathrm{n}} \text { jim }\left(s a^{\mathrm{n}} \text { jjom }\right) \text { 'I want' } \\
& \text { b. } \quad \mathbb{S}-\mathrm{a}^{+}{ }^{\mathrm{h}} \mathrm{t} \quad\left(s a^{h} \mathrm{t} f\right) \quad \text { 'I give' }
\end{aligned}
$$

$$
\begin{aligned}
& \text { Suffixal /s/ to } \mathbf{C}_{(. . .)} \mathbf{V} \text { stems } \\
& \text { a. wic }+\mathrm{i}-\mathrm{u}-\mathrm{S} \text { (wi.cjo.us) 'I rise' } \\
& \text { b. } \mathrm{pe}^{\mathrm{h}}-\mathrm{u}-\mathrm{S} \quad\left(\mathrm{pja}^{h} \cdot u s\right) \text { 'I lie' }
\end{aligned}
$$

2.4.1 Completive and Stative $1 / \mathrm{s} /$ can co-occur with the Aspect markers - Completive, Stative, and Subordinate - as can be seen, for example, in the 1st singular Completive (25) or Stative (26) of $\mathbf{V}($...) $\mathbf{C}$ bases. Like the $2 \mathrm{I}+$ Asp cases ( $(2.3)$, these forms have two mobile consonantal affixes. But unlike those cases, there is only one available vowel (the left-side theme vowel). One affix will attach to that vowel (avoiding a cluster), but the other will be stuck next to a consonant. This is the first (real) case where epenthesis is unavoidable. Nevertheless, the relative left/right order of $1 / \mathrm{s} /$ and Asp reveals the relative ranking of their alignment constraints: 1 /s/ surfaces at the right edge while Asp is displaced all the way to the left; hence (27). Notably, even though Asp is attaching in the phonotactically preferred location, it is $1 / \mathrm{s} /$ whose alignment preferences are being satisfied. Therefore, under this analysis, there is no direct connection between morphological priority and phonotactic optimization. The two considerations co-exist, but are distinct.

1st singular Completive of $\mathbf{V}_{(. . .)} \mathbf{C}$ bases $\mathrm{n}-\mathrm{u}+\mathrm{k}^{\mathrm{w}} \mathrm{al}-a \mathrm{~s}\left(\right.$ nuk $k^{w}$ alas $) \quad$ 'I am pregnant' ST-child-1
(26)

$$
\begin{aligned}
& \text { 1st singular Stative of } \mathbf{V}_{(\text {....) }} \mathbf{C} \text { bases } \\
& \mathrm{t}-\mathrm{a}+{ }^{\mathrm{h}} \mathrm{t}-\text { is }\left(t a^{h} \text { tjus) } \quad\right. \text { 'I gave (it)' } \\
& \text { CP-give-1 [(Kim, 2010:141)] }
\end{aligned}
$$

Ranking: Align-1-R $\gg$ Align-Asp-R

The tableaux in (28-29) illustrate how this works. Tableau (28) contains the maximal assortment of candidates, with all possible ordering permutations (assuming root + theme vowel to be a unit). Candidates are organized pairwise: the first shows a particular order without cluster-breaking epenthesis; the second shows that same

\begin{tabular}{|c|c|c|c|c|c|c|c|}
\hline \multicolumn{2}{|c|}{$/ \mathrm{u}+\mathrm{k}^{\mathrm{W}} \mathrm{al}, \mathrm{n}_{\mathrm{ST}}, \mathrm{s}_{1} /$} & \multirow{2}{*}{$\frac{{ }^{*} \mathrm{CC}}{* !}$} & \multirow[t]{2}{*}{ DEP } & \multicolumn{2}{|c|}{ ALIGN-1-R } & \multicolumn{2}{|c|}{ ALIGN-AsP-R } \\
\hline a. & s-uk ${ }^{\mathrm{W}}$ al-n & & & $* * * * *$ & $\left(\mathrm{u}, \mathrm{k}^{\mathrm{w}}, \mathrm{a}, \mathrm{l}, \mathrm{n}\right)$ & & \\
\hline b. & s-uk ${ }^{\mathrm{W}}$ al- $a \mathrm{n}$ & & $*$ & $*$ !***** & $\left(\mathrm{u}, \mathrm{k}^{\mathrm{w}}, \mathrm{a}, \mathrm{l}, a, \mathrm{n}\right)$ & & \\
\hline c. & n-uk ${ }^{\mathrm{w}}$ al-s & $* !$ & & & & $* * * * *$ & $\left(\mathrm{u}, \mathrm{k}^{\mathrm{w}}, \mathrm{a}, \mathrm{l}, \mathrm{s}\right)$ \\
\hline d. $\quad$ 的 & $\mathrm{n}-\mathrm{uk}^{\mathrm{w}} \mathrm{al}-a \mathrm{~s}$ & & $*$ & & & $* * * * * *$ & $\left(\mathrm{u}, \mathrm{k}^{\mathrm{w}}, \mathrm{a}, \mathrm{l}, a, \mathrm{~s}\right)$ \\
\hline e. & $\mathrm{uk}^{\mathrm{W}}$ al-s-n & *!* & & * & (n) & & \\
\hline f. & $\mathrm{uk}^{\mathrm{W}} \mathrm{al}-a \mathrm{~s}-a \mathrm{n}$ & & $* * !$ & ** & $(a, \mathrm{n})$ & & \\
\hline g. & $\mathrm{uk}^{\mathrm{w}}$ al-n-s & $* ! *$ & & & & * & (s) \\
\hline h. & $\mathrm{uk}^{\mathrm{w}} \mathrm{al}-a \mathrm{n}-a \mathrm{~s}$ & & $* * !$ & & & $* *$ & $(a, \mathrm{~s})$ \\
\hline i. & s-n-uk ${ }^{\mathrm{w}}$ al & $* !$ & & $* * * * *$ & $\left(\mathrm{n}, \mathrm{u}, \mathrm{k}^{\mathrm{w}}, \mathrm{a}, \mathrm{l}\right)$ & $* * * *$ & $\left(\mathrm{u}, \mathrm{k}^{\mathrm{w}}, \mathrm{a}, \mathrm{l}\right)$ \\
\hline j. & $\mathrm{s} a-\mathrm{n}-\mathrm{uk}^{\mathrm{w}} \mathrm{al}$ & & * & $* ! * * * * *$ & $\left(\mathrm{an}, \mathrm{u}, \mathrm{k}^{\mathrm{W}}, \mathrm{a}, \mathrm{l}\right)$ & $* * * *$ & $\left(\mathrm{u}, \mathrm{k}^{\mathrm{w}}, \mathrm{a}, \mathrm{l}\right)$ \\
\hline $\mathrm{k}$. & n-s-uk ${ }^{\mathrm{W}}$ al & $* !$ & & $* * * *$ & $\left(\mathrm{u}, \mathrm{k}^{\mathrm{w}}, \mathrm{a}, \mathrm{l}\right)$ & $* * * * *$ & $\left(\mathrm{~s}, \mathrm{u}, \mathrm{k}^{\mathrm{w}}, \mathrm{a}, \mathrm{l}\right)$ \\
\hline 1. & $\mathrm{n} a-\mathrm{s}-\mathrm{uk}^{\mathrm{W}} \mathrm{al}$ & & $*$ & $* ! * * *$ & $\left(\mathrm{u}, \mathrm{k}^{\mathrm{w}}, \mathrm{a}, \mathrm{l}\right)$ & $* * * * * *$ & $\left(a, \mathrm{~s}, \mathrm{u}, \mathrm{k}^{\mathrm{w}}, \mathrm{a}, \mathrm{l}\right)$ \\
\hline
\end{tabular}
order with all clusters broken up by an epenthetic vowel. The ranking $\left\{{ }^{*} \mathrm{CC} \gg \mathrm{DEP}\right\}$ automatically prefers the epenthesis candidates to the cluster candidates. Since there are no orderings that, without epenthesis, lack clusters, the winning candidate will violate DeP (minimally). Extra DeP violations (28f,h) are not tolerated if mis-alignment (i.e. mobility) is possible. The choice among the minimal DeP violators - pulled out in (29) — is adjudicated by the highest-ranked alignment constraint: ALIGN-1-R. From this we see that avoidance of the extra DEP violation causes mobility of Stative /n/ ([n]) in this case.

Tableau for 1st person singular Completive/Stative of $\mathbf{V}_{(. . .)} \mathbf{C}$ bases 
Reduced tableau for 1 st person singular Completive/Stative of $\mathbf{V}_{(\text {...) }} \mathbf{C}$ bases

\begin{tabular}{|c|c|c|c|c|}
\hline$/ \mathrm{u}+\mathrm{k}^{\mathrm{W}} \mathrm{al}, \mathrm{n}_{\mathrm{ST}}, \mathrm{s}_{1} /$ & $* \mathrm{CC}$ & DEP & ALIGN-1-R & ALIGN-AsP-R \\
\hline b. $\quad$ s-uk ${ }^{\mathrm{W}}$ al-an & & $*$ & $* ! * * * * * \quad\left(\mathrm{u}, \mathrm{k}^{\mathrm{w}}, \mathrm{a}, \mathrm{l}, a, \mathrm{n}\right)$ & \\
\hline d. $\mathrm{n}-\mathrm{uk}^{\mathrm{w}} \mathrm{al}-a \mathrm{~s}$ & & $*$ & & $* * * * * * \quad\left(\mathrm{u}, \mathrm{k}^{\mathrm{w}}, \mathrm{a}, \mathrm{l}, a, \mathrm{~s}\right)$ \\
\hline $\mathrm{s} a-\mathrm{n}-\mathrm{uk}^{\mathrm{w}} \mathrm{al}$ & & $*$ & $* ! * * * * * \quad\left(a \mathrm{n}, \mathrm{u}, \mathrm{k}^{\mathrm{w}}, \mathrm{a}, \mathrm{l}\right)$ & $\left(\mathrm{u}, \mathrm{k}^{\mathrm{w}}, \mathrm{a}, \mathrm{l}\right)$ \\
\hline $\mathrm{n} a-\mathrm{s}-\mathrm{uk}^{\mathrm{W}} \mathrm{al}$ & & * & $\left(\mathrm{u}, \mathrm{k}^{\mathrm{w}}, \mathrm{a}, \mathrm{l}\right)$ & $* * * * * * \quad\left(a, \mathrm{~s}, \mathrm{u}, \mathrm{k}^{\mathrm{w}}, \mathrm{a}, \mathrm{l}\right)$ \\
\hline
\end{tabular}

Crucial rankings, and supporting candidate comparisons, are identified in (30):

$$
\begin{aligned}
& \text { Rankings: } \\
& \text { a. } \quad * \mathrm{CC} \gg \text { DEP } \\
& \text { b. DEP } \gg \text { ALIGN-ASP-R } \\
& \text { c. ALIGN-1-R } \gg \text { ALIGN-ASP-R }
\end{aligned}
$$

$$
\begin{array}{r}
{[(28 \mathrm{~d}) \succ(28 \mathrm{c})]} \\
{[(28 \mathrm{~d}) \succ(28 \mathrm{~h})]} \\
{[(28 \mathrm{~d}) \succ(28 \mathrm{~b}, \mathrm{j})]}
\end{array}
$$

The morphology again conspires to make a perfect $\mathbf{C}_{(. . .)} \mathbf{V}$ base minimal pair unavailable, because the intransitive suffix $/ \mathrm{u} /$ is required with such roots. ${ }^{6}$ The vowel of ITR / $\mathrm{u} /$ allows for optimal alignment without phonotactic problems. So, Align-1-R $\gg$ Align-AsP-R (ranking (30c)) determines the outcome on its own (31). This shows that the interactive mobility of $1 / \mathrm{s} /$ and Completive/Stative can be explained in

\begin{tabular}{|c|c|c|c|}
\hline$/$ tfut $+\mathrm{u}, \mathrm{t}_{\mathrm{CP}}, \mathrm{u}_{\mathrm{ITR}}, \mathrm{s}_{1} /$ & $* \mathrm{CC} / \mathrm{DEP}$ & ALIGN-1-R & ALIGN-ASP-R \\
\hline tfutu-s-u-t & & $* ! *$ & \\
\hline b. futu-t-u-s & & & $(\mathrm{u}, \mathrm{s})$ \\
\hline s-u-tfutu-t & & $* ! * * * * * \quad(\mathrm{u}, \mathrm{t}, \mathrm{u}, \mathrm{t}, \mathrm{u}, \mathrm{t})$ & \\
\hline t-u-tfutu-s & & & $* * * ! * * * \quad(\mathrm{u}, \mathrm{t}, \mathrm{u}, \mathrm{t}, \mathrm{u}, \mathrm{s})$ \\
\hline
\end{tabular}
exactly the same way as the other types of mobility discussed thus far.

1st person singular Completive/Stative (Intransitive) of $\mathbf{C}_{(. . .)} \mathbf{V}$ bases

i. tfut+u-t-u-s (tfututus) 'I sat down' (intrans.) sit-CP-ITR-1 [(Kim, 2010:141, ex. 15g)]

2.4.2 Subordinate In Kim's $(2008,2010)$ analysis, the Subordinate patterns exactly like the Completive and Stative. But the parallel analysis actually picks out a distinction. This is not evident from simple Subordinates, which exhibit the special 1st person Subordinate portmanteau allomorph /n/ (SB1), as seen in (32). (Compare equivalent Completives in (33), where CP /t/ co-occurs with 1 /s/.) However, the Future Subordinate does allow (in fact requires) SB1/n/ to co-occur with 1/s/, as shown in (34-35).

$$
\begin{aligned}
& \text { 1st pers. Subordinates [(Kim, 2008:263)] } \\
& \text { a. } \mathbf{V}_{(. . .)} \mathbf{C} \text { nara }^{\eta} g \text { nara }{ }^{\eta} \text { gan } \\
& {\left[\mathbf{n}-\mathrm{a}+\mathrm{ra}^{\mathrm{g}} \mathrm{g}\right] \quad\left[\mathrm{n}-\mathrm{a}+\mathrm{ra}^{\mathrm{g}} \mathrm{g}-\mathrm{an}\right]} \\
& \text { SB1-do SB1-do-PL } \\
& \text { b. } \mathbf{C}(. . .) \mathbf{V} w e^{h} k j a n \quad w e^{h} k j a n u n \\
& \text { [we } \left.{ }^{\mathrm{h}} \mathrm{k}+\mathrm{e}-\mathbf{n}\right] \quad\left[\mathrm{we}^{\mathrm{h}} \mathrm{k}+\mathrm{e}-\mathbf{n}-\mathrm{u}-\mathrm{n}\right] \\
& \text { born-SB1 born-SB1-ITR-PL }
\end{aligned}
$$

$$
\begin{aligned}
& \text { 1st pers. Future Subordinate }\left(\mathrm{V}_{(. . .)} \mathrm{C}\right) \\
& \mathrm{s}-\mathrm{i}-\mathrm{n}-\mathrm{a}+{ }^{\mathrm{h}} \mathrm{t}\left(\operatorname{sina}^{h} \mathrm{t}\right) \quad \text { '(that) I will give (it)' } \\
& \text { 1-FUT-SB 1-give [(Kim, 2010:141)] }
\end{aligned}
$$

1st pers. Completives [(Kim, 2008:276, 277)]

$$
\begin{aligned}
& \text { a. } \mathbf{V}_{(. . .)} \mathbf{C} \text { tara }{ }^{\eta} \text { gas tara }{ }^{\eta} \text { gasan } \\
& {\left[\mathbf{t}-\mathrm{a}+\mathrm{ra}^{\mathrm{g}} \mathrm{g}-a \mathbf{s}\right] \quad\left[\mathrm{t}-\mathrm{a}+\mathrm{ra}^{\mathrm{g}} \mathrm{g}-a \mathbf{s}-a \mathrm{n}\right]} \\
& \text { CP-do-1 CP-do-1-PL } \\
& \text { b. } \mathbf{C}(\text { (...) } \mathbf{V} \text { wicjotus wicjotusun } \\
& \text { [wic }+\mathbf{i}-\mathbf{t}-\mathrm{u}-\mathbf{s}] \quad[\mathrm{wic}+\mathrm{i}-\mathrm{t}-\mathrm{u}-\mathrm{s}-\mathrm{un}] \\
& \text { rise-CP-ITR-1 rise-CP-ITR-1-PL }
\end{aligned}
$$

\section{1st pers. Future Subordinate $\left(\mathrm{C}_{(\ldots)} \mathrm{V}\right)$ $\mathrm{s}-\mathrm{i}-\mathrm{t}$ fut $+\mathrm{u}-\mathrm{n}$ (fitfutun) '(that) I will sit' 1-FUT-sit-SB 1 [Kim, 2010:141)]}

With the extra vowel provided by FUT /i/, these two consonantal affixes display typical interactive mobility, exactly parallel to the 2 nd person Completive/Stative Intransitives. In these cases (37-38), SB $1 / \mathrm{n} /$ always surfaces further to the right than 1 /s/. This gives us the ranking in (36). Since FUT /i/, just like 2 /e/, always

\footnotetext{
6 With examples like (31), Intransitive /u/'s alignment constraint (ALIGN-ITR-R) turns out to do no work, and not be involved in any critical rankings. I verified this using OTSoft (Hayes et al., 2013), where I considered additional candidate orders, e.g. [tgutu-[u-t- $u \mathrm{~s}$ ], [tfutu-t- $u \mathrm{~s}-\mathrm{u}]$ ] (exponent of $/ \mathrm{u} /$ boxed, epenthetic vowel in italics).
} 
surfaces on the left, it has a left-alignment constraint. As long as ALIGN-Fut-L $\gg$ ALIGN-SB-R, we derive the correct outcomes for the two respective base shapes, as shown in (37) and (38).

Ranking: ALIGN-SB-R $\gg$ ALIGN-1-R

Tableau for 1st person Future Subordinate of $V_{(\ldots)} C$ bases

\begin{tabular}{|c|c|c|c|c|c|}
\hline$/ \mathrm{a}+{ }^{\mathrm{h}} \mathrm{t}, \mathrm{r}$ & $1, \mathrm{i}_{\mathrm{FUT}}, \mathrm{s}_{1} /$ & ALIG & FUT-L & ALIGN-SB-R & ALIGN-1-R \\
\hline a. & $s-a^{h} t f-i-n$ & $* * ! *$ & $\left(\mathrm{~s}, \mathrm{a}^{\mathrm{h}}, \mathrm{t}\right)$ & & \\
\hline b. & $n-a^{h} t f-i-s$ & $* * ! *$ & $\left(\mathrm{n}, \mathrm{a}^{\mathrm{h}}, \mathrm{f}\right)$ & $\left(\mathrm{a}^{\mathrm{h}}, \mathrm{t}, \mathrm{i}, \mathrm{s}\right)$ & \\
\hline 䟚 & $s-i-n-a^{h} t$ & * & (s) & $\left(a^{\mathrm{h}}, \mathrm{f}\right)$ & $* * * * \quad\left(\mathrm{i}, \mathrm{n}, \mathrm{a}^{\mathrm{h}}, \mathrm{f}\right)$ \\
\hline d. & $n-i-s-a^{h} t$ & * & (n) & $* * * ! * \quad\left(i, s, a^{h}, f\right)$ & $\left(a^{\mathrm{h}}, \mathrm{f}\right)$ \\
\hline
\end{tabular}

Tableau for 1st person Future Subordinate of $\mathbf{C}_{(. . .)} \mathbf{V}$ bases

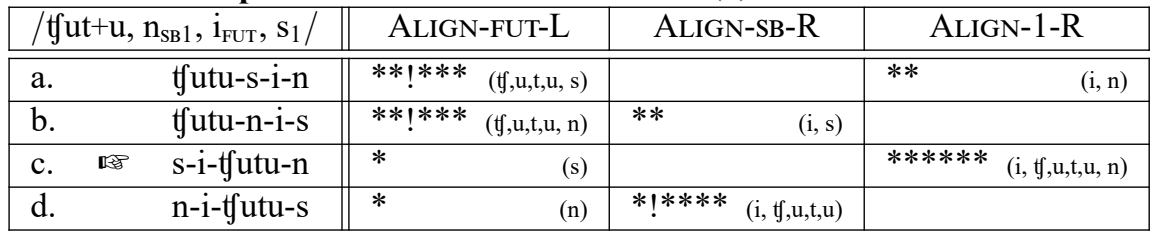

The fragment $\left\{{ }^{*} \mathrm{CC} \gg \mathrm{DEP}\right\}$ must dominate ALIGN-FUT-L in order to avoid better-aligned epenthesis candidates, e.g. *[i-tfutu-s-un] for tableau (38). The full rankings (all crucial) are pulled out in (39). The conflation of Completive/Stative with Subordinate is no longer tenable, as evident from the paradoxical rankings in (40). This is because it is purely left/right order that reflects alignment rankings (see Trommer 2001), unlike Kim's cyclic layered system, where sequential attachment is reflected by inside-out ordering.

$$
\text { Rankings: }{ }^{*} \mathrm{CC} \gg \text { DeP } \gg \text { Align-Fut-L } \gg \text { Align-SB-R } \gg \text { Align-1-R }
$$

$$
\begin{aligned}
& \text { Paradoxical Asp rankings } \\
& \text { a. Ranking (39): ALIGN-SB-R } \gg \text { ALIGN-1-R } \\
& \text { b. } \quad \text { Ranking (30): ALIGN-1-R } \gg \text { ALIGN-“AsP”-R }
\end{aligned}
$$

$$
[“ \mathrm{ASP} ”=\{\mathrm{CP}, \mathrm{ST}\}]
$$

Separating out Subordinate from Completive and Stative is probably desirable. ${ }^{7}$ Completive and Stative are clearly aspectual morphemes. But Subordinate explicitly does not carry aspectual information (Kim, 2008:263), and should probably rather be characterized as some sort of mood morpheme (ibid.: Ch. 6.2.1).

2.5 2nd person Intransitive Future Subordinate and ranking summary All remaining alignment rankings are resolved by the 2nd sing. Intrans. Future Subordinate (41-42). Fut /i/ always appears further left than 2 /e/. Since both are left-aligned morphemes, this yields the ranking in (43). Similarly, 2I /r/always appears further right than $\mathrm{SB} / \mathrm{m} /$. Since both are right-aligned morphemes, this yields the ranking in (44).

$$
\begin{aligned}
& \text { 2nd Intrans. Future Subordinate }\left(\mathbf{V}_{(. . .)} \mathbf{C}\right) \\
& \text { i-m-e-r-u+c }(\text { imeruc }) \\
& \text { FUT-SB-2-2I-eat } \quad \text { [(Kim, 2010:141)] }
\end{aligned}
$$

2nd Intrans. Future Subordinate $\left(\mathrm{C}_{(\mathrm{.} .) \mathrm{V})}\right.$ i-m-e-wic+i-r (imewicjor) 'you will get up' FUT-SB-2-rise-2I

[(Kim, 2010:141)]

$$
\text { Ranking: ALIGN-FUT-L } \gg \text { ALIGN-2-L }
$$

Ranking: ALIGN-2I-R $\gg$ ALIGN-SB-R

This resolves all crucial rankings among alignment constraints used thus far. These are summarized in (45).

$$
\begin{aligned}
& \text { Total ranking: *CC } \gg \text { DEP } \gg \text { ALIGN-FUt-L } \gg \text { ALIGN-2-L } \gg \text { ALIGN-2I-R } \gg \text { ALIGN-SB-R } \gg \text { Align- } \\
& \begin{array}{l}
\text { 1-R } \gg \text { ALIGn-AsP-R } \\
\text { (all rankings crucial) }
\end{array}
\end{aligned}
$$

\footnotetext{
7 To be clear, Kim only says that the three morphemes are "mutually exclusive" (Kim, 2008:331). She does not say that they all belong to the same category in any meaningful sense.
} 


\section{Unexpected epenthesis and morphosyntactic structure}

The parallel analysis developed above makes a prediction not inherent to Kim's cyclic analysis: no verbword that begins in a vowel should display cluster-breaking epenthesis. This statement has been true of all cases examined thus far. However, one class of affix consistently violates this prediction: plural agreement. The default plural agreement marker is $/ \mathrm{n} /{ }^{8}$ It always surfaces as a suffix, indeed the rightmost suffix in the word. In (46), where there are enough right-side vowels for all the right-oriented consonantal affixes, PL /n/ surfaces as the rightmost suffix with no epenthesis. In (47), where there aren't enough right-side vowels, it again surfaces as the rightmost suffix, with preceding epenthesis, along with prefixal realization of $1 / \mathrm{s} /$.

$$
\begin{aligned}
& \text { 2nd person Plural Intransitive } \left.\left(\mathbf{C}_{(. . .)}\right) \mathbf{V}\right) \\
& \text { i-wic+i-r-u-[n (iwicjorun) 'you (pl.) rise' } \\
& \text { 2-rise-2I-ITR-PL } \\
& \text { [(Kim, 2008:252)] }
\end{aligned}
$$

$$
\begin{aligned}
& \text { 1st person Plural Atemporal }\left(\mathbf{V}_{(. . .)} \mathbf{C}\right) \\
& \mathrm{s}-\mathrm{a}+{ }^{\mathrm{n}} \mathrm{jim}-a \mathrm{an} \text { (sa } a^{\mathrm{n}} \text { jjoman) 'we (excl.) want' } \\
& \text { 1-want-PL }
\end{aligned}
$$

This is what we'd expect from a consonantal affix with a high-ranking right-alignment constraint. However, when PL $/ \mathrm{n} /$ attaches to a $\mathbf{V}_{(. . .)} \mathbf{C}$ stem (48), we find something unexpected: it surfaces in suffixal position and requires epenthesis. ${ }^{9}$ If it were behaving like other affixes in the language, the uncovered initial vowel would lead it (or another consonantal affix) to migrate leftward so as to avoid epenthesis.

Phonotactically unnecessary epenthesis in plural forms

[(Kim, 2008:249, 257, 279)]
a. e-c-in (icjon)
2-eat-PL 'you (pl.) eat (s.t.)'
b. $\mathrm{e}^{\mathrm{h}} \mathrm{t} \mathrm{t}-i \mathrm{n}\left(i^{h}\right.$ tjon $)$
2-give-PL
'you (pl.) give'

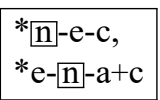
$*\left[\mathrm{n}-\mathrm{e}-{ }^{\mathrm{h}} \mathrm{t}\right.$ $* \mathrm{e}-\mathrm{n}-\mathrm{a}+{ }^{\mathrm{h}} \mathrm{t}$
c. $\quad \mathrm{e}-{ }^{\mathrm{n}}$ jim- $a$ n $\left(i^{\mathrm{n}}\right.$ jjoman $)$ 2-want-PL 'you (pl.) want'
d. e-r-u+c-in (irucjon) 2-2I-eat-PL 'you (pl.) eat' (generic)
e. $\quad \mathrm{i}-\mathrm{m}-\mathrm{e}-{ }^{\mathrm{h}} \mathrm{t}-i \mathrm{n}$ (ime $e^{h}$ tjon $)$ FUT-SB-2-give-PL 'you (pl.) will give'

We can characterize this unexpected behavior in a simple way: right-alignment of the plural affix is more important than avoiding epenthesis, which translates into the ranking in (49). Integrating this ranking fragment, we now correctly prefer candidate $(50 \mathrm{~b})$, which right-aligns PL $/ \mathrm{n} /$ and epenthesizes before it,

\begin{tabular}{|c|c|c|c|c|c|}
\hline \multicolumn{2}{|c|}{$/{ }^{\mathrm{n}} \mathrm{jim}, \mathrm{e}_{2}, \mathrm{n}_{\mathrm{PL}} /$} & ALIGN-PL-R & ${ }^{*} \mathrm{CC}$ & DEP & ALIGN-2-L \\
\hline a. & e- ${ }^{\mathrm{n}}$ fim-n & & $* !$ & & \\
\hline b. $\quad$ 畹 $/ \odot$ & $\mathrm{e}^{-}{ }^{\mathrm{n}} \mathrm{jim}-a \mathrm{n}$ & & & $*(!)$ & \\
\hline c. & n-e- ${ }^{\mathrm{n}}$ fim & $* ! * * * \quad\left(\mathrm{e},{ }_{\mathrm{j}}^{\mathrm{n}}, \mathrm{i}, \mathrm{m}\right)$ & & & $*$ \\
\hline d. & n fim-e-n & & & & $\begin{array}{ll}* * * & \left({ }^{\mathrm{n}} \mathrm{f}, \mathrm{i}, \mathrm{m}\right)\end{array}$ \\
\hline
\end{tabular}
over candidate (50c), which moves PL /n/ to the left at the expense of ALIGN-PL-R. However, the current ranking actually predicts, incorrectly, that the left-oriented $2 / \mathrm{e} /$ morpheme should move rightward to host the right-aligned PL $/ \mathrm{n} /$. That is to say, the DEP violation incurred by $(50 \mathrm{~b})$ is worse than the extra alignment violations incurred by (50d), and the latter should be selected. A quirk of the phonology suggests a solution.

Ranking: ALIGN-PL-R $\gg$ DEP

\footnotetext{
8 There is also a special 3rd person plural agreement marker / hw/, which predictably alternates between [-f, -w, -h, -Ø] (Kim, 2008:80-82), and 1st person inclusive "plural" markers /-r, $-{ }^{(\mathrm{h})}$ ts/. These behave exactly like /n/.

9 The prefixal theme vowel /a/ is absent in (48a-c,e) (though present elsewhere in the respective paradigms). It is not clear whether this is deletion under hiatus or morphological non-insertion. For simplicity, I assume the latter.
} 
3.1 A (non-)cyclic solution Huave has a process of diphthongization, which regularly applies in wordfinal closed syllables where vowel and coda disagree in backness (Kim, 2008:Ch. 3). This process is illustrated in (51a), the singular form corresponding to the plural form currently under discussion (51b).

a. Diphthongization in 2nd sing. (expected): $/ \mathrm{e}_{2}-{ }^{\mathrm{n}} \mathrm{fim} / \rightarrow\left[\mathrm{i}^{\mathrm{n}} \mathrm{jjom}\right]\left({ }^{*}\left[\mathrm{i}^{\mathrm{n}} \mathrm{jim}\right]\right) \quad[(\mathrm{Kim}, 2008: 249)]$

b. Diphthongization in 2nd pl. (unexpected): $/ \mathrm{e}_{2}{ }^{-}{ }^{\mathrm{n}} \mathrm{jim}-\mathrm{n} / \rightarrow\left[\mathrm{i}^{\mathrm{n}} \mathrm{jjoman}\right]\left(*^{\mathrm{j}}\left[\mathrm{i}^{\mathrm{n}} \mathrm{jiman}\right]\right)$

What we observe is that the diphthongization proper to the singular surfaces in its corresponding plural outside of its proper context. This relationship is not limited to this particular example. Rather, for all singular forms which regularly undergo final diphthongization, their plural forms show overapplication of diphthongization. ${ }^{10}$ This suggests that a special relationship holds between singulars and plurals.

While a cyclic phonological approach could generate these facts (see, e.g., Noyer 2013), a parallel approach relying on Base-Derivative (BD) Correspondence Theory (Benua 1997) can also do the job. If the singular serves as the base of correspondence for the plural, faithfulness to the regularly derived diphthong in the singular can induce diphthongization in the plural, even though its context is not met. Faithfulness along this same BD-correspondence relation can solve the ordering problem in (50).

The problematic candidate $(50 \mathrm{~d}) /(52 \mathrm{~d})$ is the only one which reorders the morphemes present in the singular; namely, it switches the order of the root and the 2 /e/ morpheme. Therefore, if there is faithfulness to the singular not only for diphthongization, but also for something like LinEARITY (McCarthy \& Prince, 1995), then the same correspondence/faithfulness relation that generates overapplication of diphthongization can generate ordering faithfulness as well. This is shown in (52) with a cover constraint FAITH-BD.

\begin{tabular}{|c|c|c|c|c|c|}
\hline $\begin{array}{l}\text { INPUT: } /{ }^{\mathrm{n}} \mathrm{jim}, \mathrm{e}_{2}, \mathrm{n}_{\mathrm{PL}} / \\
\text { BASE: }\left[\mathrm{i}^{\mathrm{n}} \mathrm{jjom}\right] \text { (singular) }\end{array}$ & FAITH-BD & Align-PL-R & $:{ }^{*} \mathrm{CC}$ & DEP & Align-2-L \\
\hline $\begin{array}{lll}\text { a. } & \text { e- }{ }^{\mathrm{n}} \mathrm{jim}-\mathrm{n} & {\left[\mathrm{i}^{\mathrm{n}} \mathrm{jjomn}\right]}\end{array}$ & & & $* !$ & & \\
\hline $\mathrm{e}^{-} \mathrm{fim}^{\mathrm{n}}-a \mathrm{n}\left[\mathrm{i}^{\mathrm{n}} \mathrm{fjoman}^{\mathrm{a}}\right]$ & & & 1 & * & \\
\hline n-e- ${ }^{\mathrm{n}} \mathrm{jim} \quad\left[\right.$ ne $\left.^{\mathrm{n}} \mathbf{j} \mathbf{j o m}\right]$ & & $* ! * * * \quad\left(e^{\left.n_{\mathrm{f}}, \mathrm{i}, \mathrm{m}\right)}\right.$ & & & \\
\hline$\left[{ }^{\mathrm{n}}\right.$ jimjan $]$ & $* !$ & & 1 & & $\left({ }^{\mathrm{n}} \mathrm{f}, \mathrm{i}, \mathrm{m}\right)$ \\
\hline
\end{tabular}

3.2 The MAP In Kim's cyclic analysis, the distribution of mobile and immobile consonantal affixes is arbitrary, based on which cophonology it happens to have. There is no correlation between (im)mobility and hierarchical structure or linear order. On the other hand, the parallel analysis does correlate position with immobility (i.e. epenthesis-tolerance), in the following way. Plural morphemes are immobile because their alignment constraint outranks DEP. All other consonantal morphemes (with one caveat) ${ }^{11}$ are mobile because their alignment constraint ranks below DeP. The fact that ALIGN-PL-R dominates DeP means it also outranks all other alignment constraints. Therefore, plural is always rightmost and it can induce epenthesis.

This correlation yields further insights when viewed from the perspective of the "Mirror Alignment Principle" (MAP; Zukoff to appear), a framework for morpheme ordering where alignment rankings directly reflect morphosyntactic structure:

Mirror Alignment Principle: If a terminal node $\alpha$ asymmetrically c-commands a terminal node $\beta$, then the alignment constraint referencing $\alpha$ dominates the alignment constraint referencing $\beta$.

[ $\approx$ If $\alpha$ c-commands $\beta \rightarrow$ ALIGN- $\alpha \gg$ ALIGn- $\beta$ ]

${ }^{10}$ Thank you to Yuni Kim (p.c.) for confirming that this is a correct generalization of the data available in Kim (2008).

${ }^{11}$ There $i s$ one other immobile consonantal affix: Causative $/{ }^{\mathrm{h}} \mathrm{f} /$, exemplified in (i-iii) below (data from Kim 2010:138). CAUS appears close to the root, so it should have a low-ranking alignment constraint. This means it should move around to satisfy Dep. Example (i) shows that this is (probably) not the case. It should be noted that this affix isn't productive.

(i) $\quad \mathrm{a}+\mathrm{wi}{ }^{\mathrm{n}} \mathrm{d}-\underline{i}^{\mathrm{h}} \mathbf{t}$-e $\left(a w i^{n} d i^{h} t f e\right)$

twist-CAUS-REFL

'S/he twists (his/her body)'

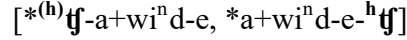

(ii) $\quad \mathrm{t}-\mathrm{a}+\mathrm{t}$ up- $i^{\mathbf{h}} \mathbf{t}$ - $-i \mathrm{~s}-\mathrm{an}_{\text {(tatfupi }}{ }^{\mathrm{h}}$ tfisan)

CP-fill-CAUS-1-PL

'We (excl.) filled (it)' (iii) $\quad l \mathrm{e}^{\mathrm{\eta}} \mathrm{g}+\mathrm{e}-\mathbf{h}^{\mathbf{h}} \mathbf{t}-e t\left(l e^{\eta} g e^{h}\right.$ tjat $)$

straighten-CAUS-CP

'It straightened' 
This approach generates "Mirror Principle" (MP) ordering (Baker, 1985), where exponents of morphemes lower down in the syntactic tree appear closer to the root than exponents of morphemes higher up in the tree. This can be demonstrated with the schematic example in (54). The MAP converts this tree structure into the ranking relations in (55), which generate MP-compliant order, as shown in (56). (I give right-alignment constraints for the affixes here, but any combination of alignment direction will yield MP-compliance.)

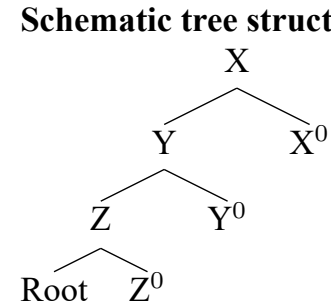

(55)

\author{
MAP-determined rankings for (54) \\ i. $\mathrm{X}^{0}$ c-commands $\mathrm{Y}^{0}$ and $\mathrm{Z}^{0} \rightarrow$ \\ Align-X-R $\gg$ Align-Y-R, Align-Z-R \\ ii. $\mathrm{Y}^{0}$ c-commands $\mathrm{Z}^{0} \rightarrow$
}

Align-Y-R $\gg$ ALIGn-Z-R

MAP-driven MP-compliant order for (54)

\begin{tabular}{|ll||c|c|c|}
\hline \multicolumn{2}{|c|}{ Root, $\mathrm{X}, \mathrm{Y}, \mathrm{Z} /$} & Align-X-R & Align-Y-R & Align-Z-R \\
\hline \hline a. & Root-X-Y-Z & $* ! *$ & $*$ & \\
\hline b. & Root-Y-X-Z & $* !$ & $* *$ & \\
\hline c. & Root-X-Z-Y & $* ! *$ & & $*$ \\
\hline d. & Root-Z-X-Y & $* !$ & & $* *$ \\
\hline e. & Root-Y-Z-X & & $* * !$ & $*$ \\
\hline f. & Root-Z-Y-X & & $*$ & $* *$ \\
\hline
\end{tabular}

The MAP allows us to make predictions about, or "reverse engineer", the hierarchical structure from the phonological analysis, in the following way:

MAP-based reverse engineering: A crucial ranking between alignment constraints in the phonology implies an asymmetric c-command relation in the morphosyntax. ${ }^{12}$

Now consider the ranking fragment in (58), extracted from (52) above. This ranking was determined based on phonological analysis alone: the relative ranking of ALIGN-PL-R and ALIGN-2-L can be determined only based on their joint interaction with epenthesis. Using MAP-based reverse engineering, we generate a hypothesis something like (59a), where the NUMBER head is (morpho)syntactically higher than the PERSON head. The same relationship can be gleaned from 1st person plural forms like $\left[a^{n} \neq j o m a\left[n\left({ }^{*} n a^{n}\right] j o m a[S)(\mathrm{Kim}, 2008: 249)\right.\right.$ based purely on alignment.

Ranking: Align-PL-R $\gg$ DEP $\gg$ ALIGN-2-L

\section{Reverse-engineered morphosyntactic structure of Number and Person}

a. (Second Person) Plurals

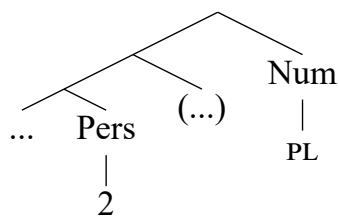

b. (Second Person) Singulars

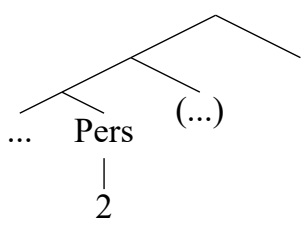

Much of the literature (e.g. Trommer 2001, Harbour 2016) from various domains — including semantics, syntax, and morphology — has been converging on the idea that, cross-linguistically, NuMBER is (typically, maybe universally) structurally higher than PERSON. Viewed in the context of the MAP, Huave thus presents phonological evidence for this same conclusion.

Notably, the structure predicted by the MAP converges with the structure implied by the BD-faithfulness component of the present analysis. Building on Brame (1974) and other work in cyclic phonology, most

\footnotetext{
${ }^{12}$ The MAP is not fully bidirectional (Zukoff, to appear); it can only serve as a hypothesis generator, not prove structure.
} 
researchers working within Base-Derivative Correspondence Theory agree that, in order for a form to function as a base of correspondence, it (at least proto-typically) must (i) be a "free-standing output form" and (ii) constitute "a subset of the grammatical features of the derived form" (Kager, 1999:282). As long as we assume that Huave singulars are underspecified for number (59b), the singular will meet the standard criteria for basehood if we adopt the morphosyntactic structure for the plurals predicted by the MAP (59a).

\section{Conclusion}

This paper has demonstrated that mobile affixation in Huave can be modeled with a fully parallel phonological approach, in addition to the "cyclic, layered" approach developed by Kim $(2008,2010,2015 \mathrm{a}, \mathrm{b})$. Violable, gradient alignment constraints indexed to individual morphemes, comprising a single language-wide ranking, govern competition between those morphemes for position in the output. ${ }^{13}$ This is possible because of a previously unrecognized generalization about the left/right stability of affix order across the language:

(60) Huave affix ordering generalization: For any two affixes of the same phonological shape, those affixes' relative left/right order is the same across all forms in which they co-occur.

The "desired" order (in terms of alignment) can be interrupted by the force of higher-ranked constraints against consonant clusters $\left({ }^{*} \mathrm{CC}\right)$ and epenthesis (DEP). This explains why only consonantal affixes are mobile. "Mobility" can thus be characterized as excess alignment violation to avoid a cluster/epenthesis.

One noteworthy difference from Kim's analysis is that the immobility of the plural morphemes correlates with their order: the ranking of alignment constraints with respect to DEP governs mobility, but it also serves as a pivot for the relative ranking of alignment constraints with respect to each other, which is what determines left/right order. This generalization can only be captured in a parallelist approach. When further tied in with the Mirror Alignment Principle (Zukoff, to appear), this same distinction comports with cross-linguistic tendencies/universals about the relative structure of Person and Number, and considerations of "base-hood" with respect to Base-Derivative Correspondence Theory.

\section{References}

Baker, Mark (1985). The Mirror Principle and Morphosyntactic Explanation. Linguistic Inquiry 16:3, $373-415$.

Benua, Laura (1997). Transderivational Identity: Phonological Relations Between Words. PhD Dissertation, University of Massachusetts, Amherst.

Brame, Michael K. (1974). The Cycle in Phonology: Stress in Palestinian, Maltese, and Spanish. Linguistic Inquiry 5:1, 39-60.

Harbour, Daniel (2016). Impossible Persons. MIT Press, Cambridge, MA.

Hayes, Bruce, Bruce Tesar \& Kie Zuraw (2013). OTSoft 2.5, software program, http://www.linguistics.ucla.edu/people/ hayes/otsoft/.

Kager, René (1999). Optimality Theory. Cambridge University Press, Cambridge.

Kim, Yuni (2008). Topics in the Phonology and Morphology of San Francisco Del Mar Huave. PhD Dissertation, University of California, Berkeley.

Kim, Yuni (2010). Phonological and Morphological Conditions on Affix Order in Huave. Morphology 20:1, $133-163$.

Kim, Yuni (2015a). Edge-Based Prosodic Mapping and the Prefix-Stem Boundary in Huave. Bui, Thuy \& Deniz Özylldız (eds.), NELS 45, GLSA, Amherst, MA, vol. 2, 111-124, http://repository.essex.ac.uk/21261/.

Kim, Yuni (2015b). Mobile Affixation Within a Modular Approach to the Morphology-Phonology Interface. Manova, Stela (ed.), Affix Ordering Across Languages and Frameworks, Oxford University Press, Oxford, 111-123.

McCarthy, John J. \& Alan Prince (1993). Generalized Alignment. Booij, Geert \& Jaap van Marle (eds.), Yearbook of Morphology 1993, Kluwer, 79-153.

McCarthy, John J. \& Alan Prince (1995). Faithfulness and Reduplicative Identity. Beckman, Jill, Suzanne Urbanczyk \& Laura Walsh Dickey (eds.), Papers in Optimality Theory, GLSA, Amherst, MA, 249-384.

Noyer, Rolf (2013). A Generative Phonology of San Mateo Huave. International Journal of American Linguistics 79:1, $1-60$.

Trommer, Jochen (2001). Distributed Optimality. PhD Dissertation, University of Potsdam.

Zukoff, Sam (to appear). The Mirror Alignment Principle: Morpheme Ordering at the Morphosyntax-Phonology Interface. Natural Language \& Linguistic Theory, https://ling.auf.net/lingbuzz/005374.

${ }^{13}$ Zukoff (to appear) argues that alignment rankings co-vary with alternations in morphosyntactic structure. Therefore, the language's morphosyntax needs to be scrutinized further to confirm the generality of the ranking across derivations. 